|| ISSN(online): 2589-8698 || ISSN(print): 2589-868X || International Journal of Medical and Biomedical Studies

Available Online at www.ijmbs.info

PubMed (National Library of Medicine ID: 101738825)

Index Copernicus Value 2018: 75.71

\title{
DIFFERENT METHODS OF FIXATION OF SEMITENDINOSUS GRAFTS IN ARTHROSCOPIC
} RECONSTRUCTION OF ANTERIOR CRUCIATE LIGAMENT

Rajiv Roy ${ }^{1}$, Alok Sobhan Datta ${ }^{2}$, Mritunjoy Roy ${ }^{3}$

${ }^{1}$ Assistant Professor, Department of Orthopaedics, North Bengal Medical College and Hospital.

${ }^{2}$ Associate Professor, Department of Orthopaedics, North Bengal Medical College and Hospital.

${ }^{3}$ Post Graduate Trainee, Department of Orthopaedics, North Bengal Medical College and Hospital.

Article Info: Received 02 May 2019; Accepted 18 June. 2019

DOI: https://doi.org/10.32553/ijmbs.v3i6.330

Address for Correspondence: Dr. Alok Sobhan Datta, Associate Professor, Department of Orthopaedics, Institute of Postgraduate Medical Education and Research, Kolkata.

Conflict of interest: No conflict of interest.

\section{Abstract}

BACKGROUND: The Anterior Cruciate Ligament $(\mathrm{ACL})$ is the most commonly injured ligament in the human body. Earlier treatment of ACL injury was mainly restricted to sportsmen, but has increased over the years because of awareness and accessibility to treatment facilities. Arthroscopic reconstruction is now the goldstandard for the treatment of $A C L$ tear.

MATERIALS AND METHODS: This study was conducted at IPGME \& R, Kolkata in the department of Orthopaedics, where forty patients with single knee injury were taken into consideration, the injury being more than two months old, in the age group 20-50 years, with clinically significant knee instabilities and confirmed on MR imaging.

RESULTS: This was a prospective randomised study where $95 \%$ of the patients were male. The outcome was based on regaining pre-injury status and recovery was based on pre- and post-operative clinical and radiological findings and marked according to Tegner- Lysholm scale.

CONCLUSION: Clinical and radiological (MRI) proved knee instabilities due to standardised Anterior Cruciate Ligament injury were best treated by arthroscopic repair using semi-tendinosus graft, which provided to be the gold-standard treatment protocol.

Keywords: ACL Injury, Knee Instability, Arthroscopic Repair, Semitendinosus Graft.

\section{Introduction}

Anterior cruciate ligament is most commonly injured ligament, which provides stability to the knee. Previously the concern regarding $A C L$ injury was largely restricted mainly amongst the sportsmen as they required a stable knee most, but now-a-days there is a change in this trend, due to increased awareness of people and easier availability of facilities.

Arthroscopic reconstruction with tendon graft is now the gold standard for the treatment of $A C L$ tear. Among the different graft materials, autologous semitendinosus graft is most popular.

This study deals with the results of different methods of fixation in arthroscopic $A C L$ reconstruction using semitendinosus graft.
This work concerns only about semitendinosus graft (Single bundle). The graft was fixed with tibial tunnel in one end and with femoral tunnel on the other end. The method of fixation was any one of the following:

1. Titanium screw in both femoral and tibial tunnel.

2. Bio-absorbable screw in both femoral and tibial tunnel

3. Endobutton-Mersilene tape for femoral tunnel and bio-absorbable screw for tibial tunnel.

In our study, we evaluated the results of different fixation methods used to fix the semitendinosus graft in arthroscope assisted anterior cruciate ligament reconstruction. Of all the ligaments providing stability to the knee join, $A C L$ is most commonly injured.

The anterior cruciate ligament is the primary restraint to the anterior tibial displacement, accounting for approximately $85 \%$ of the resistance to the anterior 
drawer test when the knee is at 90 degrees of flexion and neutral rotation. Selective sectioning of the anterior cruciate ligament has shown that the anteromedial band is tight in flexion, providing the primary restraint, whereas the posterolateral bulky portion of this ligament is tight in extension.

The posterolateral bundle provides the principal resistance to hyperextension. Tension in the anterior cruciate ligament is least at 30 to 40 degrees of knee flexion. The anterior cruciate ligament also functions as a secondary restraint on tibial rotation and varusvalgus angulation at full extension.

Investigators have studied the biomechanical properties of anterior cruciate ligament. Noyes, in a comprehensive biomechanical study, determined the ultimate load to be $1725 \pm 269 \mathrm{~N}$; the stiffness, $182 \pm 33$ $\mathrm{N} / \mathrm{mm}$; and the energy absorbed to failure,12.8 \pm 2.2 $\mathrm{N}-\mathrm{m}$. Woo et al., in younger specimens, found the ultimate load to be $2160 \pm 157 \mathrm{~N}$ and the stiffness $242 \pm 28 \mathrm{~N} / \mathrm{mm}$.

Most of the ACL injuries often occur during sports. The injury can happen following a sudden force acting on a straight or slightly flexed knee while the foot is firmly placed on the ground, when changing directions rapidly, sudden deceleration when running, or landing from a jump. This type of injury is common in soccer, skiing, hockey, polo, rugby and other sports with lots of stop-and-go movements and lots of body contact, jumping, or weaving. Falling off a ladder or missing a step on a staircase are other likely causes. The classic history of an anterior cruciate ligament injury begins with a noncontact deceleration, jumping, or cutting action.

An ACL injury can cause small or medium tears of the ligament, a complete tear of the ligament (Rupture), a separation(avulsion) of the ligament from the tibia or femur, or a separation of the ligament and part of the bone from the rest of the bone (Avulsion fracture). When any of these occur, the tibia translates abnormally forward under the femur, with a sense of the knee giving out or buckling.

The prognosis for a torn $\mathrm{ACL}$ after conservative management is often unfavourable, with the recovery and rehabilitation period usually very long. Even patients with partial $A C L$ tears may have instability following conservative management. After a complete $A C L$ tear, some patients are unable to participate in cutting or pivoting-type sports, while others have instability even during normal activities, such as walking.

With the increasing trend of diagnosed $A C L$ injury in our day to day life and the demand for returning to one's normal activity as early as possible, surgical treatment for torn $\mathrm{ACL}$ has become the standard protocol.

Messner K, Maletius W. Eighteen- to Twenty-FiveYear Follow-up After Acute Partial Anterior Cruciate Ligament Rupture. Am J Sports Med 1999;27(4):455459. Anterior cruciate ligament due to its poor potential of intrinsic repair Maletius W, Messner K. Eighteen- to Twenty-Four-Year Follow-up After Complete Rupture of the Anterior Cruciate Ligament. Am J Sports Med 1999;27Clancy WG, Ray JM, Zoltan DJ. Acute tears of anterior cruciate ligament. Surgical versus conservative treatment. J Bone Joint Surg [Am] 1988;70:1483-1488. Andersson C, Odensten M, Good $L$, et al. Surgical or non-surgical treatment of acute rupture of the anterior cruciate ligament. A randomized study with long-term follow-up. J Bone Joint Surg [Am] 1989; 71:965-974...Aho AJ, Lehto MUK, Kujala UM. Repair of the anterior cruciate ligament: Augmentation versus conventional suture of fresh rupture. Acta Orthop Scand 1986; 57:3453Kaplan N, Wickiewicz T, Warren R. Primary surgical treatment of anterior cruciate ligament ruptures. A long-term follow-up study. Am J Sports Med 1990;18(4):354-358.is generally replaced by a substitute graft made of tendon. Commonly used grafts are; bone patellar tendon bearing graft and semitendinosus-gracilis graft. In this study only semitendinosus graft is used. Arthroscopic reconstruction of $A C L$ with muscle tendon graft or bone-tendon-bone graft is the gold standard treatment for ACL tear.

Various options, namely bio-absorbable screws, titanium screws, Endobutton-suture wheel, Endobutton-Mersilene tape are available for fixation of the graft. Graft fixation is the crucial step because without proper fixation stability cannot be offered to the knee. Again there is no clear-cut demarcation about which fixation method is best.

\section{MATERIALS AND METHODS}

This study was conducted in the Department of Orthopaedics, Institute of Post Graduate Medical Education \& Research and S.S.K.M. Hospital, Kolkata20, from December 2011 to October 2013. In this 
prospective randomised study, 40 patients (40 knees) were taken into consideration.

\section{Study population}

Patients attending Orthopaedics OPD of IPGME\&R, SSKM Hospital with isolated traumatic ACL tears of more than 2 months duration, in the age group 20$50 y e a r s$ of age, symptomatic knee instability, positive Pivot shift test, Lachman test and confirmed by MRI findings.

\section{Inclusion Criteria}

- Isolated, traumatic ACL tear.

- More than 2 months duration.

- Symptomatic knee instability.

- 20-50 years of age.

- Positive Pivot-shift test.

- Positive Lachman test.

- MRI finding suggesting $A C L$ tear.

Exclusion Criteria

- Non traumatic ACL tear.

- $\mathrm{ACL}$ tears lesser 2 month duration.

- Less than 20 years or more than50 years of age.

- Non demanding patient.

- $\quad \mathrm{ACL}$ tear associated with other ligament injuries. Outcomes were defined on the basis of regaining pre

Injury status of the knee in respect of movement, stability of the knee, reduction in pain, swelling and returning to one's normal activity level. Outcome evaluation was done by preoperative and postoperative clinical and radiological findings, and Tegner-Lysholm score.

\section{RESULTS}

In this prospective randomised study, 40 patients (40 knees) were taken into consideration. Among them $38(95 \%)$ were males and 2 were females (5\%). All the patients were followed up at least for six months. Outcomes defined on the basis of regaining pre injury status of the knee in respect of movement, stability of the knee, reduction in pain, swelling and returning to one's normal activity level. Outcome evaluation was done by preoperative and postoperative clinical and radiological findings, Tegner-Lysholm score.

The above table shows that majority of the patients were male (95\%). Among the affected males mostly were from age group 20-29 years, and among the affected females majority were from age group 40-50 years. The average age of affected

\begin{tabular}{|c|c|c|}
\hline AGE & Male & Female \\
\hline 20-29 years & 25 & 0 \\
\hline 30-39 years & 10 & 0 \\
\hline 40-50 years & 3 & 2 \\
\hline Total & 38 & 2 \\
\hline \multicolumn{2}{|c|}{ Table 1: Variation of age \& Sex } \\
\hline
\end{tabular}

\begin{tabular}{|c|c|c|}
\hline $\begin{array}{c}\text { Method of } \\
\text { Fixation }\end{array}$ & $\begin{array}{c}\text { Number } \\
\text { of } \\
\text { patients }\end{array}$ & Percentage \\
\hline $\begin{array}{c}\text { Titanium screw for both } \\
\text { femoral and tibial } \\
\text { tunnel(Group-I) }\end{array}$ & 10 & $25 \%$ \\
\hline $\begin{array}{c}\text { Bio-screw for both femoral and } \\
\text { tibial tunnel(Group-II) }\end{array}$ & 10 & $25 \%$ \\
\hline $\begin{array}{c}\text { Bio-screw for Tibial tunnel and } \\
\text { Endobutton-Mersilene } \\
\text { loop for femoral tunnel } \\
\text { (Group-III) }\end{array}$ & 20 & $50 \%$ \\
\hline \multicolumn{2}{|c|}{ Table 2: Distribution of patients according to the } \\
method of fixation \\
\hline \multicolumn{2}{|c|}{}
\end{tabular}

\begin{tabular}{|c|c|c|c|}
\hline Interval & 2-6 month & $7-12$ month & 13-22 month \\
\hline Male & 25 & 10 & 3 \\
\hline Female & 0 & 1 & 1 \\
\hline Total & 25 & 11 & 4 \\
\hline Percentage & 62.5 & 27.5 & 10 \\
\hline
\end{tabular}

The above table shows that most of the cases $(25,62.5 \%)$ were operated within 2-6 months, $27.5 \%$ cases operated within 7-12months, only 4 cases(10\%) were operated after 12 months.

\begin{tabular}{|c|c|c|c|c|}
\hline $\begin{array}{c}\text { Time period in } \\
\text { months }\end{array}$ & Male & Female & Total & Percentage \\
\hline 0-6 months & 2 & 2 & 4 & $10 \%$ \\
\hline 7-12 months & 6 & 0 & 6 & $15 \%$ \\
\hline $13-22$ months & 30 & 0 & 30 & $75 \%$ \\
\hline \multicolumn{5}{|c|}{ Table Duration of follow up } \\
\hline
\end{tabular}

The above table shows that more than $75 \%$ patients were followed up for $13-22$ months, $15 \%$ patients were followed up for 7-12 months and only $10 \%$ patient were followed up for 6 months.

\begin{tabular}{|c|c|c|}
\hline Complications & Male & Female \\
\hline Superficial infection & 3 & 0 \\
\hline Deep infection & 0 & 0 \\
\hline Tunnel blow out & 0 & 0 \\
\hline Recurrent knee effusion & 2 & 0 \\
\hline Iatrogenic neurovascular injury & 0 & 0 \\
\hline Repeat operation for fixation failure & 0 & 0 \\
\hline \multicolumn{2}{|c|}{ Table 5: Incidence of complications } \\
\hline
\end{tabular}

The table shows incidence of complications. Superficial infection occurred in 3 patients. Recurrent episodes of effusion occurred in 2 patients. 


\section{Dr. Alok Sobhan Datta et al, International Journal of Medical and Biomedical Studies (IJMBS)}

\begin{tabular}{|c|c|c|c|c|c|}
\hline \multirow[b]{2}{*}{$\begin{array}{l}\text { Sl. } \\
\text { No. }\end{array}$} & \multirow[b]{2}{*}{ Age } & \multirow[b]{2}{*}{ Sex } & \multicolumn{3}{|c|}{ Lysholm Knee Score } \\
\hline & & & $\begin{array}{c}\text { At } \\
\text { Presentation }\end{array}$ & $\begin{array}{c}1 \\
\text { Month }\end{array}$ & $\begin{array}{c}6 \\
\text { Months }\end{array}$ \\
\hline 1 & 20 & $\mathrm{M}$ & 62 & 72 & 90 \\
\hline 2 & 22 & $\mathrm{M}$ & 60 & 74 & 100 \\
\hline 3 & 20 & M & 72 & 90 & 100 \\
\hline 4 & 20 & M & 74 & 84 & 95 \\
\hline 5 & 24 & $\mathrm{M}$ & 57 & 69 & 84 \\
\hline 6 & 23 & $\mathrm{M}$ & 63 & 76 & 85 \\
\hline 7 & 25 & $\mathrm{M}$ & 66 & 78 & 86 \\
\hline 8 & 27 & $\mathrm{M}$ & 69 & 80 & 88 \\
\hline 9 & 27 & $\mathrm{M}$ & 72 & 80 & 90 \\
\hline 10 & 27 & $\mathrm{M}$ & 75 & 82 & 87 \\
\hline 11 & 26 & $\mathrm{M}$ & 63 & 85 & 94 \\
\hline 12 & 28 & $\mathrm{M}$ & 76 & 85 & 95 \\
\hline 13 & 29 & $\mathrm{M}$ & 78 & 82 & 90 \\
\hline 14 & 28 & $\mathrm{M}$ & 80 & 100 & 100 \\
\hline 15 & 27 & $\mathrm{M}$ & 78 & 90 & 94 \\
\hline 16 & 25 & $\mathrm{M}$ & 82 & 94 & 94 \\
\hline 17 & 25 & $\mathrm{M}$ & 80 & 90 & 96 \\
\hline 18 & 22 & $\mathrm{M}$ & 70 & 78 & 94 \\
\hline 19 & 21 & $\mathrm{M}$ & 74 & 96 & 96 \\
\hline 20 & 21 & $\mathrm{M}$ & 85 & 90 & 94 \\
\hline 21 & 24 & $\mathrm{M}$ & 90 & 95 & 95 \\
\hline 22 & 29 & $\mathrm{M}$ & 80 & 100 & 100 \\
\hline 23 & 28 & $\mathrm{M}$ & 64 & 85 & 95 \\
\hline 24 & 28 & $\mathrm{M}$ & 60 & 84 & 100 \\
\hline 25 & 21 & $\mathrm{M}$ & 57 & 76 & 90 \\
\hline \multirow[b]{2}{*}{$\begin{array}{l}\text { SL. } \\
\text { No. }\end{array}$} & \multirow[b]{2}{*}{ Age } & \multirow[b]{2}{*}{ Sex } & \multicolumn{3}{|c|}{ Lysholm Knee Score } \\
\hline & & & $\begin{array}{c}\text { At } \\
\text { Presentation }\end{array}$ & $\begin{array}{c}1 \\
\text { Month }\end{array}$ & $\begin{array}{c}6 \\
\text { Months }\end{array}$ \\
\hline 26 & 30 & $\mathrm{M}$ & 56 & 78 & 96 \\
\hline 27 & 30 & $\mathrm{M}$ & 60 & 80 & 96 \\
\hline 28 & 32 & M & 63 & 75 & 95 \\
\hline 29 & 34 & $\mathrm{M}$ & 64 & 76 & 90 \\
\hline 30 & 34 & $\mathrm{M}$ & 68 & 80 & 96 \\
\hline 31 & 35 & $\mathrm{M}$ & 70 & 85 & 100 \\
\hline 32 & 37 & $\mathrm{M}$ & 65 & 80 & 100 \\
\hline 33 & 39 & $\mathrm{M}$ & 60 & 82 & 100 \\
\hline 34 & 38 & $\mathrm{M}$ & 57 & 84 & 95 \\
\hline 35 & 38 & $\mathrm{M}$ & 58 & 85 & 100 \\
\hline 36 & 40 & $\mathrm{~F}$ & 68 & 95 & 100 \\
\hline 37 & 43 & $\mathrm{~F}$ & 72 & 96 & 96 \\
\hline 38 & 46 & $\mathrm{M}$ & 56 & 88 & 88 \\
\hline 39 & 48 & M & 60 & 78 & 80 \\
\hline 40 & 50 & $\mathrm{M}$ & 63 & 100 & 100 \\
\hline \multicolumn{3}{|c|}{ Average score } & 68.1 & 74.4 & 94.1 \\
\hline \multicolumn{6}{|c|}{$\begin{array}{c}\text { Table 6: Lysholm knee score of the patients at the time } \\
\text { of presentation, at } 1 \text { month and at } 6 \text { month } \\
\text { postoperative follow-up }\end{array}$} \\
\hline
\end{tabular}

The table shows that average Lysholm score of the patients at the time of presentation was 68.1. At 1 month postoperative follow-up the average score was 74.4 and at 6month postoperative follow-up the average score was 94.1

Evaluation of results of different methods of fixation in arthroscopic ACL reconstruction using semitendinosus graft: Statistical analysis.

\section{Software Used}

- Statistica version 6 [Tulsa, Oklahoma: StatSoft Inc., 2001]

- GraphPad Prism version 5 [San Diego, California: GraphPad Software Inc., 2007]
Descriptive statistics of numerical variables - Group $1[n=10]$

\begin{tabular}{|c|c|c|c|c|c|c|c|c|c|}
\hline & \multicolumn{2}{|c|}{$\begin{array}{l}\text { Valid N } \\
\text { Upper Std.De }\end{array}$} & Meall & Median & \multicolumn{3}{|c|}{ Minimum Maximum } & \multicolumn{2}{|c|}{ Lower } \\
\hline & & & & & \multicolumn{5}{|c|}{ Quartile Quartile } \\
\hline Age & 10 & 23.4 & 22.0 & 20.0 & 29 & 20.0 & 27.0 & 3.57 & 1.13 \\
\hline Injopint & 10 & 6.6 & 5.5 & 3.0 & 12 & 5.0 & 9.0 & 2.80 & 0.88 \\
\hline Dumpe & 10 & 22.3 & 22.5 & 18.0 & 22 & 21.0 & 24.0 & 1.95 & 0.62 \\
\hline LKS_B & 10 & 69.4 & 72.0 & 57.0 & 82 & 62.0 & 74.0 & 8.34 & 2.64 \\
\hline LKS_lm & 10 & 83.4 & 83.0 & 72.0 & 96 & 76.0 & 90.0 & 7.95 & 2.51 \\
\hline LKS 6m & 10 & 93.0 & 92.0 & 85.0 & 100 & 90.0 & 96.0 & 4.85 & 1.53 \\
\hline
\end{tabular}

All numerical variables listed above are normally distributed by Kolmogorov-Smirnoff goodness-of-fit test.

Descriptive statistics of numerical variables - Group $2[\mathrm{n}=10]$

\begin{tabular}{|c|c|c|c|c|c|c|c|c|c|}
\hline & $\begin{array}{l}\text { Valid } \\
\text { Uppel }\end{array}$ & td.Dev. & $\begin{array}{l}\text { Mean } \\
\text { Stand }\end{array}$ & $\mathrm{Me}$ & & Minimum M & ile Qu & Lov & \\
\hline & El'rol' & & & & & & & & \\
\hline Age & 10 & 27.5 & 27.0 & 21.0 & 37 & 22.0 & 30.0 & 5.34 & 1.69 \\
\hline InjOpInt & 10 & 5.9 & 5.5 & 2.0 & 11 & 4.0 & 7.0 & 2.92 & 0.92 \\
\hline DurnFU & 10 & 16.6 & 18,0 & 9.0 & 21 & 15.0 & 18.0 & 3.53 & 1.12 \\
\hline LKS_B & 10 & 68.7 & 66.5 & 56.0 & 85 & 60.0 & 80.0 & 9.90 & 3.13 \\
\hline LKS_lm & 10 & 83.5 & 80.0 & 74.0 & 100 & 78.0 & 90.0 & 7.79 & 2.46 \\
\hline LKS $6 \mathrm{~m}$ & 10 & 96.0 & 96.0 & 94.0 & 100 & 94.0 & 96.0 & 2.31 & 0.73 \\
\hline
\end{tabular}

Descriptive statistics of numerical variables - Group $3[\mathrm{n}=20]$

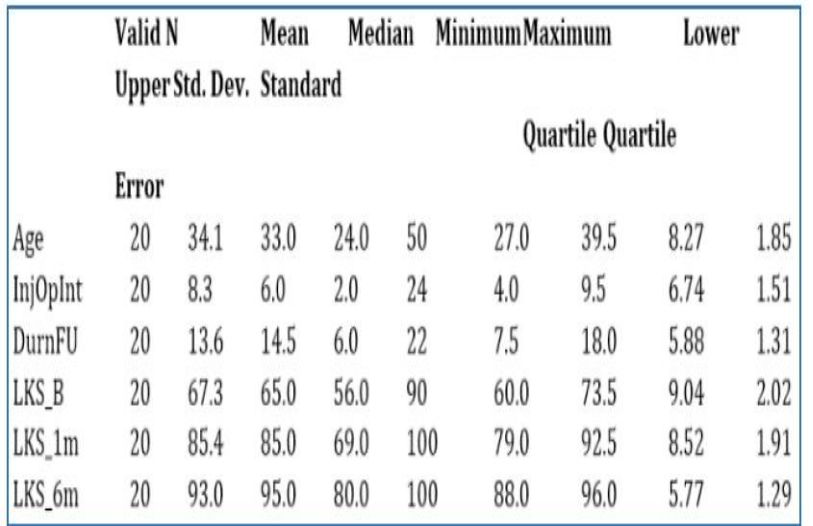

Comparison of numerical variables between Groups $\mathrm{T}$ and $\mathrm{P}$ - One-way ANOVA

\begin{tabular}{|c|c|c|c|c|c|c|}
\hline & SS & & MS & SS & & MS $\quad$ Fp \\
\hline & Effect & Effect & Effect & Error & Error & Error \\
\hline Age & 832.2750 & 2 & 416.1375 & 1670.700 & 37 & 45.154059 .21595 \\
\hline & 0.001 & & & & & \\
\hline Injopint & 42.4500 & 2 & 21.2250 & 1011.050 & 37 & 27.325680 .77674 \\
\hline & 0.467 & & & & & \\
\hline DurnFU & 504.6750 & 2 & 252.3375 & 803.300 & 37 & 21.7108111 .62267 \\
\hline & 0.000 & & & & & \\
\hline LKS_B & 33.0750 & 2 & 16.5375 & 3060.700 & 37 & 82.721620 .19992 \\
\hline & 0.820 & & & & & \\
\hline LKS_1m & 38.0750 & 2 & 19.0375 & 2495.700 & 37 & 67.451350 .28224 \\
\hline & 0.756 & & & & & \\
\hline LKS_6m & 69.0250 & 2 & 34.5125 & 892.950 & 37 & 24.133781 .43005 \\
\hline & 0.252 & & & & & \\
\hline
\end{tabular}




\section{Dr. Alok Sobhan Datta et al, International Journal of Medical and Biomedical Studies (IJMBS)}

Thus there is significant difference between groups in Age and Duration of FU, but not in other parameters compared.

\section{Comparison of change over time in Group 1}

Repeated measures ANOVA followed by Tukey's test for multiple comparison if ANOVA returns $p$ value $<0.05$

\section{LKS}

Repeated measures ANOVA No. of datasets 3 F value 54.066 $\mathrm{p}$ value $<0.001$

\begin{tabular}{|l|c|c|c|c|}
\hline $\begin{array}{l}\text { Tukey's Multiple } \\
\text { Comparison Test }\end{array}$ & Mean Diff. & q & P value & $\begin{array}{c}95 \% \text { CI } \\
\text { of diff }\end{array}$ \\
\hline LKS_B vs LKS_1m & -14.000 & 8.6738 & $<0.001$ & -19.825 to -8.1749 \\
\hline LKS_B vs LKS_6m & -23.600 & 14.622 & $<0.001$ & -29.425 to -17.775 \\
\hline LKS_1m vs LKS_6m & -9.6000 & 5.9477 & $<0.01$ & -15.425 to -3.7749 \\
\hline
\end{tabular}

Comparison of change over time in Group 2

Repeated measures ANOVA followed by Tukey's test for multiple comparison if ANOVA returns $p$ value $<0.05$

\section{LKS}

Repeated measures ANOVA No. of datasets 3 F value $55.775 \mathrm{p}$ value $<0.001$

\begin{tabular}{|l|c|c|c|c|}
\hline $\begin{array}{l}\text { Tukey's Multiple } \\
\text { Comparison Test }\end{array}$ & Mean Diff. & q & P value & $\begin{array}{c}\text { 95\% CI } \\
\text { of diff }\end{array}$ \\
\hline LKS_B vs LKS_1m & -14.800 & 8.0879 & $<0.001$ & -21.404 to -8.1959 \\
\hline LKS_B vs LKS_6m & -27.300 & 14.919 & $<0.001$ & -33.904 to -20.696 \\
\hline LKS_1m vs LKS_6m & -12.500 & 6.8310 & $<0.001$ & -19.104 to -5.8959 \\
\hline
\end{tabular}

Comparison of change over time in Group 3

Repeated measures ANOVA followed by Tukey's test for multiple comparison if ANOVA returns $p$ value $<0.05$

\section{LKS}

Repeated measures ANOVA No. of datasets $3 \quad \mathrm{~F}$ value $99.656 \mathrm{p}$ value $<0.001$

\begin{tabular}{|c|c|c|c|c|}
\hline $\begin{array}{c}\text { Tukey's Multiple } \\
\text { Comparison Test }\end{array}$ & Mean Diff. & q & P value & $\begin{array}{c}95 \% \\
\text { CI of diff }\end{array}$ \\
\hline LKS_B vs LKS_1m & -18.100 & 13.708 & $<0.001$ & -22.657 to -13.543 \\
\hline LKS_B vs LKS_6m & -25.650 & 19.425 & $<0.001$ & -30.207 to -21.093 \\
\hline LKS_1m vs LKS_6m & -7.5500 & 5.7178 & $<0.001$ & -12.107 to -2.9934 \\
\hline
\end{tabular}

Evaluating the results of different methods of fixation, no statistically significant difference was found regarding outcome
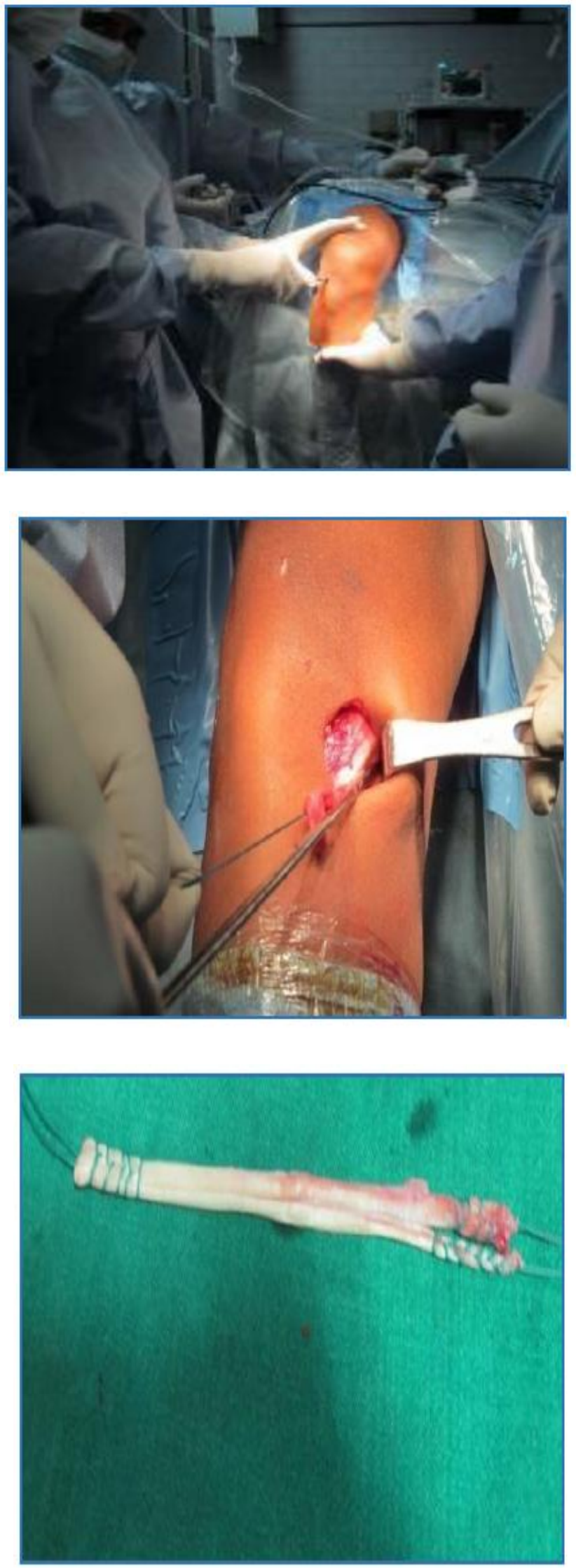


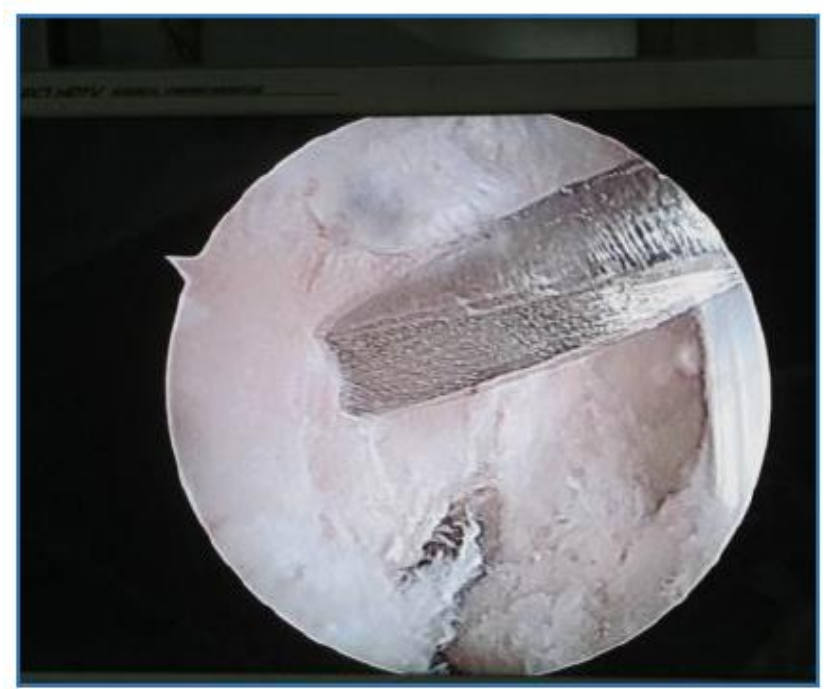

\section{DISCUSSION}

Anterior cruciate ligament is the most commonly injured ligament which provides stability to the knee. Earlier, ACL reconstruction was done by open methods but with time this went out of favour due to various drawbacks like risk of infection, long term hospital stay, joint stiffness, loss of working days, prolonged rehabilitation, and advent of arthroscopy.

Arthroscopic reconstruction with tendon graft is now the gold standard for the treatment of $\mathrm{ACL}$ tear. Among the different graft materials autologous semitendinosus graft is preferred.(1) The method of fixation of the graft is of primary importance as it is the weakest link and mainly responsible for complications. Without proper fixation the graft cannot withstand the stress generated to keep the knee stable. This study dealt with the results of different methods of fixation in arthroscopic $A C L$ reconstruction using semitendinosus graft.

Selection of 40 patients by proper clinical and radiological evaluation was based on the inclusion criteria. Among them 38 patients (95\%) were male, 2 patients (5\%) were female. Among the affected males, most were from the age group 20-29 years, and among the affected females majority were from age group 40-50 years. The average age of affected males was 29.1 years and females were 41.5 years. The male: female ratio was 19: 1 .

Most of the cases $(25,62.5 \%)$ were operated within 2-6 months, $27.5 \%$ cases were operated within 712 months, only 4 cases (10\%) were operated after 12 months.

Patients were divided in three groups according to the method of fixation chosen. Endobutton-
Mersilene tape/loop for femoral tunnel and Bioscrew for tibial tunnel was chosen as fixation method for 20 (50\%) patients(group-III), Titanium screw for both the tunnels was chosen as fixation method for $10(25 \%)$ patients (group-I), Bioscrew for both tunnels chosen as fixation method for another 10(25\%) patients(group-II).

In our study more than $75 \%$ patients were followed up for $13-22$ months, $15 \%$ patients were followed up for 7-12 months and only $10 \%$ patient were followed up for 6 months.

The average Lysholm score of the patients at the time of presentation preoperatively was 68.1. At 1 month postoperative follow-up the average score was 74.4 and at 6 month postoperative follow-up the average score was 94.1. The average Lysholm score at 6 month postoperative follow-up for Group-I patients was 93.1. The average Lysholm score for Group-II patients at 6 month postoperative follow-up was 93.4. For Group-III patients the Lysholm score at 6 month follow-up was 96.6. For all three Groups the scores were marked excellent. According to Lysholm score the criteria for grading the outcome were:

Poor -a score < 65;

Fair-a score of 65-83;

Good- a score of84-90;

Excellent- a score $>90$.

Lachman test \&Pivot-shift test were negative at 1 month and 6 months follow-up for all the patients.

Complications like superficial infection was noted in 3 patients, recurrent knee effusion occurred in 2 patients. No case of graft fixation failure requiring repeat surgery was noted.

Outcome was measured with preoperative and postoperative clinical evaluation and by the TengerLysholm scoring system .No significant difference was found between the three groups regarding outcome.

Most of the studies showed that there was no significant difference between bioabsorbable fixation material and metallic fixation devices regarding clinical outcome: pain, swelling- with- activity \& range of motion. Thus bioabsorbable screw provided a reasonable alternative to titanium screw (5) and the results were comparable.

The serial follow-up study showed significant improvement in outcome in all three groups. The 
outcome for individual groups were found to be excellent as also the average Lysholm score.

In our study we evaluated 40 patients. The results could have been more significant had the study population been a larger one with a longer follow up.

\section{SUMMARY AND CONCLUSION}

The prognosis for a torn $\mathrm{ACL}$ after conservative management is often unfavourable, with the recovery and rehabilitation period usually very long. Even patients with partial $\mathrm{ACL}$ tears may have instability after conservative management. Nonoperative treatment is a viable option for those who are willing to make lifestyle changes and avoid activities that cause recurrent instability. [16] Arthroscopic reconstruction with tendon graft is now the standard option for the treatment of $A C L$ tear. Among the different graft materials, autologous semitendinosus graft is a preferred one.

For fixation of the graft, available fixation devices are either bioabsorbable or metallic. Studies done in this field comparing the outcome between bioabsorbable and titanium fixation devices showed no significant differences. $(7,8,10,11)$

We selected 40 patients by proper clinical and radiological evaluation based on our inclusion criteria. Among them 38 patient (95\%) were males and 2 patients (5\%) were females. Among the affected males most were from age group 20-29 years, and among the affected females majority were from age group 40-50 years. The average age of affected males was 29.1 years and females were 41.5 years. The male: female ratio was 19:1

In conclusion, this procedure benefitted all the endusers with excellent results.

\section{REFERENCES}

1. Luca Capuano, Philippe Hardy, Umile Giuseppe Longo, Vincenzo Denaro, Nicola Maffulli, No difference in clinical results between femoral transfixation and bio-interference screw fixation in hamstring tendon $\mathrm{ACL}$ reconstruction-a preliminary study The Knee (2008),Volume: 15, Issue: 3, Pages: 174-179.

2. M Hamada, $K$ Shino, $S$ Horibe, $T$ Mitsuoka, $T$ Miyama, Y Shiozaki, T Mae. Comparison between different femoral fixation devices for $A C L$ reconstruction with doubled hamstring tendon graft-a biomechanical analysis-Arthroscopy-the journal of arthroscopic related surgery official publication of the Arthroscopy Association of North America and the International Arthroscopy Association (2001),Volume: 22, Issue: 6, Pages: 801-807.

3. Anna-Stina Moisala, Timo Järvelä, Antti Paakkala, Timo Paakkala, Pekka Kannus, Markku Järvinen.Comparison of the bioabsorbable and metal screw fixation after $A C L$ reconstruction with a hamstring autograft in MRI and clinical outcome:a prospective randomized study.Knee surgery sports traumatology arthroscopy official journal of the ESSKA (2008) Volume: 16, Issue: 12, Pages: 1080-1086:

4. Cameron $\mathrm{M}$, Buchgraber $\mathrm{A}$, Paller $\mathrm{H}$ et all: The natural history of anterior cruciate ligament deficient knee, changes in synovial fluid cytokine and keratin sulfate concentration, American Journal of Sports medicine,25:751,1997.

5. $P$ Kousa, $T$ L Järvinen, $P$ Kannus, $M$ Järvinen, Initial fixation strength of bioabsorbable and titanium interference screws in anterior cruciate ligament reconstruction, biomechanical evaluation by single cycle and cyclic loading, The American Journal of Sports Medicine (2001),Volume: 29, Issue: 4, Pages: 420-425.

6. Christopher Kaeding, Jack Farr, Tim Kavanaugh, Angela Pedroza, Prospective randomized comparison of bioabsorbable and titanium anterior cruciate ligament interference screws, Arthroscopy Association of North America and the International Arthroscopy Association (2005),Volume: 21, Issue: 2, Pages: 147-151.

7. Caborn DN, Urban WP Jr, Johnson DL, Nyland J, Pienkowski D,A biomechanical comparison between Bioscrew and titanium alloy interference screws for bone-patellar tendonbone graft fixation in anterior cruciate ligament reconstruction.

8. Lanny L. Johnson, M.D, G.Eda vanDyk, M.D, Department of Surgery, Michigan State University, East Lansing, Michigan, U.S.A, Metal and biodegradable interference screws: Comparison of failure strength,The Journal of Arthroscopic \& Related Surgery August 1996, Pages 452-456, Volume 12, Issue 4.

9. F.Alan Barber, M.D., a, Burton F. Elrod, M.D.b, David A. McGuire, M.D.c, Lonnie E. Paulos, M.D.d, Preliminary results of an absorbable interference screw, Arthroscopy: The journal of Arthroscopic \& related surgery. 
10. David A. McGuire, M.D., F.Alan Barber, M.D., Burton F. Elrod, M.D. Lonnie E. Paulos, M.D.,Bioabsorbable Interference screws for graft fixation in Anterior Cruciate Ligament Reconstruction, Arthroscopy: The Journal of Arthroscopic \& Related Surgery, Volume 15, Issue 5, July-August 1999, Pages 463-473.

11. DNM Caborn, $M$ Coen, $R$ Neef $t, D$ Hamilton, J Nyland, DL Johnson, Division of Orthopaedic Surgery, The University of Kentucky School of Medicine, Lexington, USA, Quadrupled semitendinosus-gracilis autograft fixation in the femoral tunnel:a comparison between a metal and a bioabsorbable interference screw, Arthroscopy: The Journal of Arthroscopic \& Related Surgery Volume 14, Issue 3, April 1998, Pages 241-245.

12. Mark Walton, Ph.D,Department of Orthopaedic Surgery, Dunedin School of Medicine, University of Otago, Dunedin, New Zealand,Absorbable and Metal Interference Screws:Comparison of graft security during healing,Arthroscopy: The Journal of Arthroscopic \& Related Surgery, Volume 15, Issue 8, November-December 1999, Pages 818826.

13. Andre Weimann, M.D.a, Mareike Rodieck, M.D.a, Thore Zantop, M.D.a, Joachim Hassenpflug, M.D.a, Wolf Petersen, M.D.b, a Department of Orthopaedic Surgery, ChristianAlbrechts University Kiel, Kiel,b Department of Trauma, Hand, and Reconstructive Surgery, Westfälische Wilhelms University Münster, Münster, Germany,Primary stability of hamstring graft fixation with biodegradable suspension versus interference screws,Arthroscopy: The Journal of Arthroscopic \& Related Surgery, Volume 21, Issue 3, March 2005, Pages 266-274.

14. Giuseppe Milano, M.D.a, Pier Damiano Mulas, M.D.b, Fabio Ziranu, M.D.b, Stefano Piras, M.D.b, Andrea Manunta, M.D.b, Carlo Fabbriciani, M.D.a,a Department of Orthopaedics, Catholic University, Rome,b Department of Orthopaedics, Sassari, Italy,Comparison Between Different Femoral Fixation Devices for $\mathrm{ACL}$ Reconstruction with Doubled Hamstring Tendon Graft:A bomechanical analysis, Arthroscopy: The Journal of Arthroscopic \& Related Surgery,Volume 22, Issue 6, June 2006, Pages 660-668.

15. Jon Olav Drogset, M.D.a, Torbjørn Grøntvedt, M.D., Ph.D.a, Vigleik Jessen, M.D.a,Agnar Tegnander, M.D., Ph.D.a, Tom Eirik Mollnes, M.D., Ph.D.b, Kåre Bergh, M.D., Ph.D.c,a Department of Orthopaedics, Trondheim University Hospital, Institute of Immunology, Trondheim, Norway,b Rikshospitalet University Hospital, University of Oslo, Oslo, Norway and Bioabsorbable Screws Used in Anterior Cruciate Ligament,Comparison of In Vitro and In Vivo Complement Activation by Metal Reconstruction

16. Daniel DM, Stone ML, Dobson B.E. et all: Fate of $A C L$ injured patients: a prospective random study, American Journal of Sports medicine, 22:632,1994. 